\title{
O objeto da segregação e o campo de concentração
}

\section{The object of segregation and the concentration camp}

\section{El objeto de la segregación y el campo de concentración}

\author{
Marcos Vinicius Brunhari* \\ Universidade do Estado do Rio de Janeiro - UERJ, Rio de Janeiro, Rio de Janeiro, \\ Brasil
}

\author{
Vinicius Anciães Darriba** \\ Universidade do Estado do Rio de Janeiro - UERJ, Rio de Janeiro, Rio de Janeiro, \\ Brasil
}

\begin{abstract}
RESUMO
O isolamento de um sujeito puro é o fundamento do saber científico, segundo Lacan (1967). Deste sujeito puro está velada a estrutura que comporta a relação com o objeto a e a implicação disso, que Lacan apregoa a uma universalização do sujeito, tem ressonâncias sobre o ser falante e, também, sobre a ordem social. O preço dos avanços civilizatórios se traduz, para além do mal-estar, em efeitos de segregação. Tais efeitos permitem que se questione o estatuto assumido pelo objeto a nesse processo, que tem por contrapartida a ampliação dos processos de segregação atrelada ao futuro de mercados comuns. No velamento da divisão do sujeito procuraremos situar um encontro forjado por meio do objeto produzido pela tecnicização da ciência, sob a injunção do Discurso do Capitalismo. Desde então, avançaremos para sustentar que a matriz para tal processo poderia estar firmada historicamente nos campos de concentração. Tal percurso permite questionar a implicação do objeto a na noção de efeito de segregação.
\end{abstract}

Palavras-chave: teoria psicanalítica, Lacan, J., segregação, campo de concentração.

\begin{abstract}
The isolation of a pure subject is the foundation of the scientific knowledge, according to Lacan (1967/unpublished). From this pure subject is veiled the structure that contains the relation to the object $a$ and the implication of this, that Lacan preaches to a universalization of the subject, has resonances on the speaking being, also, on the social order. The price of civilizational advances translates, to beyond malaise, in the effects of segregation. These effects allow to question the status assumed by the object $a$ in this process, which has as counterpart the expansion of segregation processes linked to the future of common markets. In the veiling of the division of the subject, we will try to locate an encounter forged through the object produced by the technicization of science, under the injunction of the Discourse of Capitalism. Since then, we will advance to maintain that the matrix for such a process
\end{abstract}


could be established historically in the concentration camps. This path allows us to question the implication of object a in the notion of segregation effect.

Keywords: psychoanalytic theory, Lacan, J., segregation, concentration camp.

\begin{abstract}
RESUMEN
El aislamiento de un sujeto puro es el fundamento del saber científico, según Lacan (1967). De este sujeto puro está velada la estructura que comporta la relación con el objeto a y la implicación de eso, que Lacan pregona a una universalización del sujeto, tiene resonancias sobre el ser hablante y, también, sobre el orden social. El precio de los avances civilizatorios se traduce en, además del malestar, efectos de segregación. Tales efectos permiten que se cuestione el estatuto asumido por el objeto a en ese proceso, que tiene como contrapartida la ampliación de los procesos de segregación ligada al futuro de mercados comunes. En el velamiento de la división del sujeto procuraremos situar un encuentro forjado por medio del objeto producido por la tecnicización de la ciencia, bajo la orden del Discurso del Capitalismo. Desde entonces, avanzaremos para sostener que la matriz para tal proceso podría estar firmada históricamente en los campos de concentración. Este recorrido permite cuestionar la implicación del objeto a en la noción del efecto de segregación.
\end{abstract}

Palabras clave: teoría psicoanalítica, Lacan, J., segregación, campo de concentración.

\title{
1 objeto a e o campo da partilha
}

Os desdobramentos em torno da problemática do objeto podem ser amplamente abordados na obra de Freud e no ensino de Lacan. Rabinovich (2009), de maneira exímia, estabelecem um percurso que permite esmiuçar a concatenação conceitual do objeto em Freud em uma perspectiva que leva em conta o objeto em sua articulação com o desejo, a pulsão e o amor. Esse percurso firmado pela autora atinge o ensino de Lacan em uma interpelação inicial da conceituação do objeto feita a partir do crivo dos registros imaginário e simbólico. Essa primeira interpelação se detém frente à dimensão do real como ausência de mediação, sendo que, a partir de então, "surge ali um objeto que Lacan formula como o objeto da angústia por excelência" (Rabinovich, 2009, p. 117). Esse objeto é irredutível e opera em contraponto ao simbólico e ao imaginário.

No Seminário livro 10: a angústia (2005), esse objeto será melhor delineado em uma distinção ao objeto do conhecimento e, também, como não especularizável. $\mathrm{O}$ objeto então denominado algebricamente de $a$, opera como resíduo da divisão do sujeito no campo do Outro. É como sobra do atravessamento do significante que o objeto a se caracteriza como irredutível. Ao diferenciar a cena constituída pelo Outro do mundo em que se comprime o real, Lacan localiza a angústia ao lado do que não engana. Isto que não engana não pertence à cena do significante, cuja impossibilidade de 
representar algo, tal como signo, lança-o como aquilo que engana. A angústia enquanto fenômeno é atrelada por Lacan (2005) à inquietação de um momento em que algo aparece, no nível da imagem, no lugar em que se presentificaria a falta. A investigação do fenômeno passa a estar, aqui, orientada nos termos dessa aparição, com o que é reaberta a discussão sobre o objeto da angústia, anteriormente associada a uma ausência de objeto (Freud, 1996c).

O objeto que assim entra em jogo não possui forma, não tem no espelho um reflexo. Ele se contrapõe ao significante na medida em que a angústia não se reduz ao simbólico e ao imaginário. É deste modo que Lacan (2005) retoma seu estádio do espelho, tal como foi apresentado em $O$ estádio do espelho como formador da função do eu (Lacan, 1998), agora acompanhado de um objeto irredutível ao significante. Trata-se do que vemos ele chamar de objeto $a$, aquele que tem na angústia "sua única tradução subjetiva" (Lacan, 2005, p. 113). O sinal de sua intervenção é, então, atrelado à angústia, a qual já "não é sem objeto" (p. 101).

É preciso determo-nos sobre a expressão "não sem", que não determina um objeto para a angústia tal qual se articulam objeto e medo, por exemplo, na fobia. Esta expressão de negação é elíptica e relega o objeto da angústia à condição de indeterminação. Tal condição faz com que o objeto a seja refratário a definições de objetalidade e de objetividade. A discussão sobre seu estatuto é uma contribuição lacaniana no sentido de articular o que não se encerra nas dimensões do imaginário e do simbólico. Conforme indicado, é como o que não tem reflexo no espelho do imaginário e também como irredutível ao significante que o objeto a remete ao real.

A indeterminação imaginária e a irredutibilidade simbólica do objeto a diferenciam-no daqueles objetos que, no campo da posse, podem ser compartilhados. É nesse campo que o próprio falo é questionado por Lacan (2005) em sua constituição de objeto comum que, ao ser tomado pelo agente da castração, torna-se propriedade do mesmo. Ser propriedade é um detalhe que aponta para a problemática do objeto no campo da posse. Isso pode ser destacado, por exemplo, no caso do pequeno Hans (Freud, 1996b) que, em seu devaneio, teria seu órgão genital desatarraxado como uma torneira. Não é apenas o falo que é suscetível ao corte que o dispõe a ser compartilhado, já que Lacan (2005) diferencia dois tipos de objeto no campo da posse: os que podem ser partilhados e os que não podem.

Os objetos que podem ser partilhados compõem um campo alicerçado no domínio imaginário. São objetos especularizáveis na medida em que entram em um jogo de rivalidade e acordo com o outro semelhante. Esses objetos, segundo Lacan (2005), são definidos como cotáveis, socializados e comunicáveis. São objetos de troca, e o fato de serem comuns os diferencia de outro objeto que logicamente o antecede. Antes de sucumbir à partilha que o torna um objeto de 
troca passível de especularização e rivalizado com o outro semelhante, há um estado de indivisibilidade. Tal anterioridade lógica à constituição do objeto comum define o estatuto do objeto a enquanto irredutível ao significante.

A diferenciação do objeto a tem ressonâncias conceituais e clínicas ao permitir articular o real a partir de uma formalização. Sustentaremos, ao longo do desenvolvimento do artigo, que esse objeto se encontra implicado na referência de Lacan, no ano de 1967, à noção de segregação. Tal implicação se ampara na proposição sobre um sujeito puro (1967), derivado do progresso científico, e que tem em si velada a estrutura que comporta a relação com o objeto a. A propagação da universalização desse sujeito puro coincide com a ampliação dos efeitos de segregação, a qual estaria pautada em um "futuro de mercados comuns" (Lacan, 2003a, p. 263).

Nesse processo em que a divisão do sujeito é velada situaremos um encontro que é forjado por meio do objeto produzido pela ciência, sob injunção do Discurso do Capitalismo. O encontro com esse objeto de gozo é essencial para o velamento da divisão e para a consequente purificação do sujeito que, desde então, torna-se apto à universalização. Quanto a essa última, indicaremos como estaria suposta nos efeitos de segregação. A partir daí, avançaremos para mostrar que a matriz para tal processo poderia estar, como aponta Lacan (2003a), firmada historicamente nos campos de concentração. Tal percurso permite questionar a implicação do objeto a na noção de efeito de segregação e tem sua relevância assinalada enquanto contribuição teórica aos debates concernentes ao estatuto do objeto e aos efeitos de segregação. Firmado o tal questionamento, recorreremos aos textos Proposição de 9 de outubro de 1967 sobre o psicanalista da Escola (Lacan, 2003a), Alocução sobre as psicoses da criança (2003b) e Breve discurso aos Psiquiatras (Lacan, 1967) com o objetivo de sustentar que o que se encontraria segregado a partir da universalização do sujeito puro é o objeto $a$.

\section{0 mercado do objeto comum}

É na divisão do sujeito no campo do Outro (Lacan, 2005) que o objeto a se precipita como irredutível, como aquilo que não pode ser socializado ou objetivado. Esse objeto que não é partilhável como imagem articula-se à angústia, pois é por meio de um sinal que indica sua entrada no campo da partilha. Esse objeto remonta ao que Freud (1996c) reunira como formas de perda, que são os principais momentos do aparecimento do sinal de angústia, e que foram catalogadas por Lacan (2005) em cinco níveis: oral, anal, fálico, escópico e superegoico. Distinto do objeto de troca, o a é apresentado por Lacan (2005) a partir da Banda de Moebius (Figura 
1), que, por sua constituição topológica, tem apenas uma face. Dotada de apenas uma face, esta superfície não possui reflexo especular na mesma medida em que um corte ocasiona não uma divisão, mas uma reprodução da mesma superfície.

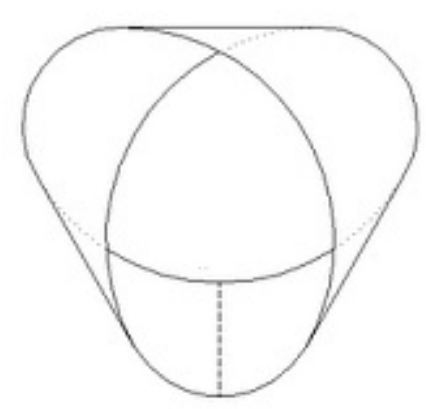

Figura 1 - "Banda de Moebius" (Lacan, 1962-63/2005, p.110)

A entrada desse objeto, disposto em uma anterioridade lógica ao significante e à constituição do objeto especularizável, no campo da partilha equivaleria a uma cisão. Lacan (2005) remete a uma metáfora embriológica em que o envoltório embrionário, como a placenta, se desprende na medida em que um corte separa o feto da genitora. Esse tecido que se desprende e cai é fruto de um corte duplo, no feto e na genitora, e funciona de maneira homóloga na relação primitiva com o seio materno. Esse objeto, em um primeiro momento, homólogo à placenta - "amboceptor" (p. 185), está acoplado ao corpo materno. Por uma cisão, algo se desprende desse objeto, ao mesmo tempo em que ele se dispõe à representação. É enquanto representável que ele pode ser substituído, por exemplo, pela mamadeira; e, principalmente, sua entrada no campo da troca o torna parcial, pois um irredutível se desprende e, ao cair, torna o objeto incompleto.

Esta conjectura estrutural do objeto, já indicada por Freud, tem no princípio de sua obra uma referência neurológica. Em seu Projeto para uma psicologia científica, Freud (1996a) descreve a representação objetal a partir da composição de neurônios: busca-se o objeto a partir de uma primeira composição entre neurônio a e neurônio $b$. Essa composição neuronal remete à busca pela satisfação e se forma como desejo. Em seguida, o investimento objetal é realizado sobre a composição constituída pela percepção possibilitada pelo encontro com um outro objeto que não o desejado. Essa é a composição entre neurônio a e neurônio c (Freud, 1996a). A não equivalência entre os neurônios $b$ e c é o que torna o objeto passível de atributos e de predicação. Já o neurônio a, constante em ambas as composições, é indicado como a Coisa (das Ding). Essa parte não é passível a atributos e Freud a alinha aos princípios morais do julgar. 
Essa problemática é explorada depois por Lacan, em seu Seminário livro 7: a ética da psicanálise (2008, p. 152), enquanto das Ding é “o que do real padece do significante". A articulação entre o que para Freud não possui atributos e o juízo moral é central nesse período do ensino de Lacan (2008, p. 95): “Minha tese é de que a lei moral se articula com a visada do real como tal, do real na medida em que ele pode ser a garantia da Coisa".

Não pretendemos aqui retomar os pormenores da discussão promovida por Lacan sobre a questão moral em sua articulação com o real. Apenas destacamos que a entrada do objeto no campo da partilha o cinde. Assim, parcialmente o objeto se torna conformável à troca, enquanto algo reportável ao real lacaniano se desprende. Isso posto, consideremos a seguinte afirmação de Lacan (2005, p. 164): "Que a moral deve ser procurada do lado do real, sem dúvida, e mais especialmente na política, não equivale a incitá-los a procurá-la, no entanto, do lado do Mercado Comum". A separação entre o real e o Mercado Comum permite compreender que os objetos partilháveis entram no campo da socialização e circulam por um mercado de trocas.

É importante salientar que essa afirmação de Lacan (2005) sobre o Mercado Comum é proferida em sequência a uma consideração sobre os campos de concentração. Segundo o psicanalista, a moral cretinizante do pós-guerra não permite um exame mais detido dos campos que têm na história uma função. A função histórica do campo de concentração não é explicitada por Lacan, mas a duração, sua condição de algo não pontual no tempo é duramente firmada pelo autor. O campo de concentração tem sua permanência histórica mascarada pela moralização e, já que a moral não deve ser procurada do lado do Mercado Comum, conforme Lacan indica, é possível questionar se o campo de concentração, de alguma maneira, se articula ao que é dessa ordem. Tal questionamento leva em consideração o estatuto do objeto no campo da partilha e deve se apoiar no avanço da reflexão sobre esse estatuto. Em seguida, para avançar assim na discussão, serão traçadas novas considerações sobre o objeto segundo as formulações lacanianas nas quais se faz referência aos efeitos de segregação.

\section{0 remanejamento das massas}

Em sua Proposição de 9 de outubro de 1967 sobre o psicanalista da Escola, Lacan (2003a) trata das estruturas asseguradas da psicanálise e, dentre estas, considera a diferenciação entre psicanálise em extensão e em intensão. Sendo a primeira relativa à presentificação da psicanálise no mundo, a segunda se ocupa, didaticamente, do preparo dos operadores da mesma. Essa 
diferenciação se sustenta na proposta da psicanálise enquanto experiência original orientada pela transferência. Diferentemente da terapêutica em que se visa um restabelecimento do estado anterior, o termo da relação transferencial aponta para um "decair de sua fantasia" (Lacan, 2003a, p. 257) e a destituição do sujeito. A destituição subjetiva é alinhada por Lacan, neste período de seu ensino, à travessia da fantasia, em que a segurança daí extraída naufraga na direção da apreensão do desejo.

Nesse momento, em seu Seminário livro 15: 0 ato psicanalítico, Lacan (1967-68) articula a destituição subjetiva ao final de análise, propondo-o como "queda do sujeito suposto saber e sua redução ao advento desse objeto a, como causa da divisão do sujeito, que vem ao seu lugar" (Aula de 10 de janeiro/1968). A destituição subjetiva da qual trata o processo analítico é a de um atravessamento no qual o sujeito dá lugar ao objeto que, isto deve ser frisado, é a causa da divisão. Lacan (1967-68) assevera tal posição ao afirmar:

O sujeito depende desta causa que o faz dividido que se chama o objeto a, eis quem assina o que é importante de ser sublinhado: que o sujeito não é a causa de si, que ele é consequência da perda e que seria preciso que ele se colocasse na consequência da perda, a que constitui o objeto a, para saber o que lhe falta (Aula de 10 de janeiro/1968)

O atravessamento da fantasia acentua a constituição do sujeito como fundada sobre a perda. O lugar a ser ocupado ao término do processo analítico é o da consequência da perda, desde onde é possível saber sobre a falta. A destituição subjetiva, dessa forma operada, assinala o decair do sujeito e da fantasia em direção ao saber sobre a falta fundamental. Assim, a destituição subjetiva pela travessia da fantasia é distinta da destituição promovida pela ciência. Segundo Lacan (2003a, p.257), o real da ciência "destitui o sujeito de modo bem diferente em nossa época quando apenas seus partidários mais eminentes, como um Oppenheimer, perdem a cabeça". Destituição que pode vir a ser sinônimo de morte e destruição, como a provocada pela bomba atômica de Oppenheimer, ela é, na Proposição, novamente associada aos campos de concentração. É assim que, como apontaremos a seguir, Lacan localiza a ampliação dos processos de segregação, que tem no que vimos emergir dos campos de concentração sua antecipação, como um imbróglio no horizonte da psicanálise.

Lacan (2003a) distingue três pontos de fuga no horizonte da psicanálise em extensão. Esses pontos delimitam uma perspectiva, projetam-se como fatos e são definidos a partir do simbólico, do imaginário e do real. Segundo Brousse (2002), por serem fatos, esses pontos de fuga são relativos ao âmbito da experiência, sendo o 
primeiro relativo à clínica; o segundo, à transmissão da psicanálise; e o terceiro, atrelado ao real, é relativo aos campos de concentração.

Os dois primeiros pontos se articulam respectivamente, então, ao simbólico e ao imaginário. O primeiro é extraído da clínica e constitui a problematização sobre o lugar ocupado pela ideologia edipiana na psicanálise. Esse ponto dispõe o Édipo como um problema, não mais como uma solução, e seu estatuto mítico é rearticulado por Lacan (2003a) em uma proposição sobre o gozo na atualidade de uma sociedade veiculada pela ciência. É da mesma forma que o segundo ponto de fuga, referente ao imaginário, constitui-se como uma crítica às instituições de psicanálise e suas identificações imaginárias, característica essa que aponta para a hierarquia das instituições psicanalíticas como que regulada pela função do pai.

O terceiro ponto de fuga é referente ao campo de concentração. Esse fato é atrelado ao real por Lacan (2003a) e evidencia o extremo de uma experiência inapreensível pelos filósofos que, segundo o autor, vagam do humanismo ao terror. Como já destacado pelo psicanalista no Seminário livro 10 (Lacan, 2005), não se reduz o campo a um momento determinado da história, esse tem antes a posição de precursor "em relação ao que se irá desenvolvendo como consequência do remanejamento dos grupos sociais pela ciência, e, nominalmente, da universalização que ela ali introduz" (Lacan, $2003 a$, p. 263). A sociedade vetorizada pela ciência tem como consequência, portanto, o remanejamento dos grupos sociais, o qual se orientaria pela universalização por ela promovida. Tal universalização, traduzida ainda por Lacan (1967), como indicaremos no próximo tópico, em termos da promoção de um sujeito puro, seria o fundamento da prática de concentração de massas humanas, fato que não é inassimilável aos psicanalistas, na medida em que tenham em conta a dimensão do real.

Levando em consideração o remanejamento que decorreria da universalização do sujeito promovida pela ciência, é relevante considerar a seguinte afirmação de Lacan (2003a, p. 263): “Nosso futuro de mercados comuns encontrará seu equilíbrio numa ampliação cada vez mais dura dos processos de segregação". Nessa menção aos mercados comuns, Lacan enfatiza sua correlação com o que nomeia processo de segregação. Segregação que se perfila no horizonte traçado por Lacan (2003b, p. 361):

Os homens estão enveredando por uma época que chamamos planetária, na qual se informarão por algo que surge da destruição de uma antiga ordem social, que eu simbolizaria pelo Império, tal como sua sombra perfilou-se por muito tempo numa grande civilização, para ser substituída por algo bem diverso e que de modo algum tem o mesmo sentido - os imperialismos, cuja questão é a seguinte: como fazer para que 
massas humanas fadadas ao mesmo espaço, não apenas geográfico, mas também, ocasionalmente, familiar, se mantenham separadas?

O processo de segregação referir-se-ia, portanto, a manter separadas massas humanas fadadas ao mesmo espaço. Esse horizonte dos mercados comuns, dos imperialismos, agencia-se, como vimos, à universalização do sujeito pela ciência. A segregação seria "o modo predominante de gozo atualmente (...), a nova solução dada ao gozo" (Brousse, 2002, p. 45). A atualidade dos efeitos de segregação, ao se apresentar como uma solução ao gozo, interroga os discursos segundo a articulação que deles estabelece, tendo por eixo sua emergência, o discurso psicanalítico.

\section{A universalização a partir do Mercado Comum}

É possível alinhar o que Lacan (2003b) nomeia acima como época planetária com a regência do Mercado Comum. A destituição de uma ordem social, simbolizada como um Império, rumo aos imperialismos tem como perspectiva o remanejamento das massas. O processo segregatório que se põe no horizonte, orientado pela universalização do sujeito da ciência, é assim regulado pelo Mercado Comum. Com o objetivo de melhor delimitar o que seria a promoção pela ciência de um sujeito puro é preciso recorrer ao Breve discurso aos Psiquiatras (Lacan, 1967). Segundo o psicanalista, a partir do nascimento da ciência no século XVII, houve um primeiro isolamento desse sujeito puro:

Ali, a partir desse momento nasceu a ciência, se posso dizer, correlativa de um primeiro isolamento do sujeito puro. Esse sujeito puro, evidentemente, não existe em nenhuma parte exceto como sujeito do saber científico. É um sujeito do qual uma parte está velada, justamente a que se expressa na estrutura fantasmática, a saber, a que comporta outra metade do sujeito e sua relação com o objeto a. (...) Há um preço com o qual se paga pela universalização do sujeito, enquanto é um sujeito falante, o homem (Lacan, 1967)

Trata-se do sujeito derivado do saber científico que se articula aos remanejamentos das hierarquias sociais, como indicamos anteriormente, e que possui uma parte de si velada. Essa parte é a que se expressa pela estrutura fantasmática ( $\$ \diamond a$ ), a qual comporta a relação do sujeito barrado com o objeto a. A obturação da estrutura fantasmática é preponderante na dominância de tal sujeito que, ao se purificar, torna-se universalizável. É diante do velamento da estrutura 
na qual o sujeito se divide em sua relação com o objeto causa de desejo, que Lacan (1967) aponta um preço a ser pago enquanto falante. Preço que, como indicaremos, encontrará no gozo uma via para problematizar a segregação, a qual refere-se, por ora, à concentração das massas humanas. Sobre a universalização do sujeito puro e a concentração das massas, Lacan (1967) afirma que os progressos da civilização se traduzirão não apenas pelo mal-estar indicado por Freud, "mas também por uma prática que verão se tornar mais estendida (...): a segregação. Aos senhores nazis, vocês poderiam ter por tais práticas um considerável reconhecimento, pois foram precursores".

Lacan vislumbra, para além do que pode traduzir o mal-estar freudiano atrelado aos progressos civilizatórios, uma prática que se tornará cada vez mais ampliada. Trata-se justamente da segregação como ponto de fuga em um horizonte no qual o remanejamento das massas encontra nos campos de concentração da Segunda Guerra Mundial seus precursores. O replicar desta prática baseada na universalização seria, então, o preço a ser pago pelo progresso do sujeito puro da ciência.

É possível indicar no ensino de Lacan, ainda no término da década de 1960, a universalização de um sujeito puro a partir do que o psicanalista propõe, como veremos, acerca do Discurso da Universidade. É no Seminário, livro 17: o avesso da psicanálise que Lacan (1992) descreve os quatro discursos (Figura 2) como aparelhos orientados pela linguagem, estruturados de modos distintos a partir do laço social. O Discurso do Mestre, da Histérica, da Universidade e do Psicanalista são arranjos em que se concatenam o significante $\left(S_{1}\right)$ com outro significante $\left(S_{2}\right)$, gerando como efeito um sujeito (\$) que tem como causa de seu desejo o objeto a. É assim que esse aparelho faz operar, de quatro maneiras distintas, a articulação entre linguagem e gozo. A rotatividade desses quatro elementos pelos quatro lugares imutáveis, designados como agente, outro, produção e verdade, é o que diferencia cada discurso quanto ao que se estabelece como impossibilidade e impotência. 


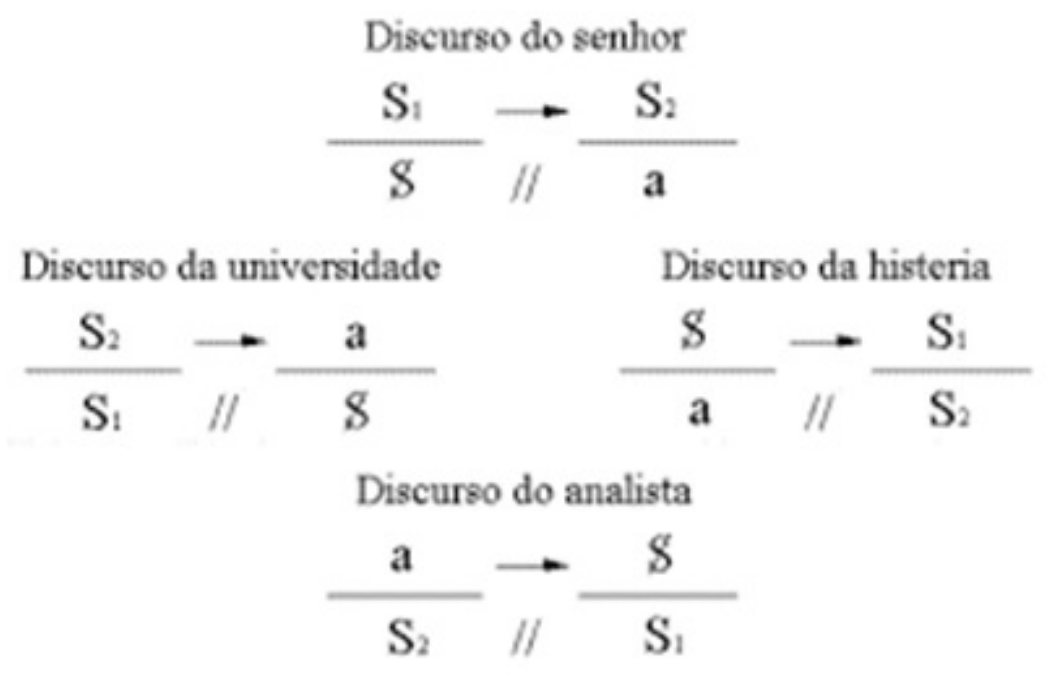

Figura 2 - Os quatro discursos (Lacan, 1969-70/1992, p.29)

Quanto ao Discurso do Mestre, $S_{1}$ é o agente que domina e tem o escravo $\left(S_{2}\right)$ como outro em uma posição de suporte do saber. Isso encontra-se fundamentado na finalidade de "mostrar que o escravo sabe, mas, ao confessar isto apenas por esse viés de derrisão, o que se oculta é que se trata exclusivamente de arrebatar do escravo sua função no plano do saber" (Lacan, 1992, p. 20). O mestre não precisa se comprometer com o saber já que o escravo se encarrega disto. Assim, instala-se a impossibilidade que não permite ao senhor recuperar um gozo perdido a partir daquilo que o escravo produz.

A impossibilidade deixa suspenso o que habita o lugar da verdade. No caso do Discurso do Mestre, no lugar de verdade está o sujeito barrado que permanece obturado, pois esse mestre objetiva uma redução de $\$$ ao $S_{1}$, a fim de suprimir sua verdade enquanto castrado. Não há relação entre o produto desse discurso, o objeto a, e o que ocupa o lugar de verdade, o \$. Há, pela impotência, uma exclusão da fantasia ( $\$ \diamond$ a). Segundo Lacan (1992, p. 114), "em seu ponto de partida fundamental, o discurso do mestre exclui a fantasia. E é isto exatamente o que faz dele, em seu fundamento, totalmente cego". A identificação de \$ com $S_{1}$ acontece na medida em que o mestre desconhece o que lhe falta; por isso exclui o que é um indício disso e consome aquilo que se produz a partir de um saber sem sujeito.

Em um giro anti-horário desde o Discurso do Mestre, no Discurso da Universidade destacamos o lugar da verdade ocupado por $S_{1}$. É pelo fato desse significante ocupar o lugar da verdade que Lacan (1992) alinha o Discurso da Universidade à ciência. Dele deriva o mandamento que impele a ciência ao incessante "Continua a saber sempre mais" ( p. 110), o qual subsidia o saber, $S_{2}$, como agente e encontra a impossibilidade diante do outro. O objeto a no lugar que 
cabe ao outro situa a posição do estudante nesse discurso, na qual o mais-de-gozar dita o que está em jogo na exploração.

Ter o $S_{1}$ como mandamento incessante da verdade não faz com que a ciência, de acordo com o Discurso da Universidade, ao tomar o sujeito como produto, deixe de encontrar um limite nisso. Perguntamos se é nos termos do Discurso do Capitalismo (Figura 3), posteriormente articulado por Lacan (1978), que se poderia pretender tal limite como ultrapassado. É o que ele escreveria como sendo sua própria constituição, na qual o mandamento de saber incessante $\left(S_{1} \rightarrow S_{2}\right)$ se conjugaria com a associação entre objeto e sujeito em uma via distinta $(a \rightarrow \$)$ da estrutura fantasmática, por se dar ali a determinação do sujeito pelo objeto. É importante frisar que Lacan (1992) localizara o que confere ao Discurso do Mestre o estilo capitalista como uma "mutação capital" (p. 178).

\section{Discurso do capitalista}

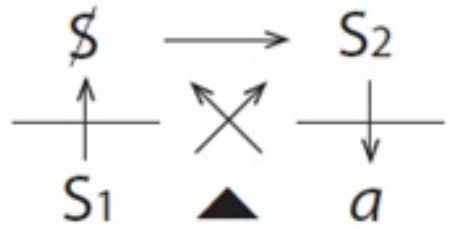

Figura 3 - Discurso do Capitalismo (Lacan, 1972/1978, p. 40)

A ciência, tomada pela ausência de limite que o Discurso do Capitalismo propõe, engendra um objeto que, enquanto produto e mais-valia, incide sobre a satisfação. Com relação a esse objeto produzido pela injunção do Discurso do Capitalismo sobre a ciência, Lacan (1992, p. 172) afirma que, "quanto aos pequenos objetos a que vão encontrar ao sair, (...) na proliferação desses objetos feitos para causar o desejo de vocês, na medida em que agora é a ciência que o governa, pensem neles como latusas". Ao operar e perceber, segundo o psicanalista, a ciência o percebe seus objetos que funcionam como ondulações, não são acessíveis aos sentidos. Esse objeto que não se circunscreve ao âmbito do ser ou do Outro, e que remete ao vento da voz humana, exige uma nova palavra para sua definição. Latusa é o neologismo lacaniano oriundo de uma referência ao espaço no qual circulam ondas hertzianas e outras que não podem ser percebidas. Esse espaço inapreensível à percepção é o mesmo no qual opera a verdade formalizada pelas coordenadas científicas. Nomeado como aletosfera, o espaço em que a ciência opera e percebe a partir da verdade é onde estão disponíveis as latusas como objetos desde aí derivados.

Tais objetos oferecidos em larga escala têm por função a causação do desejo, na medida em que são uma promessa de gozo. O encontro entre o sujeito ávido e seu objeto de gozo fabricado solucionaria o 
impasse fantasmático perpetrado pelo Discurso do Mestre. O Discurso do Capitalismo estaria a oferecer uma via em que se soluciona o impasse dissolvendo a estrutura fantasmática ( $\$ \diamond a$ ) com a inversão de sua operação: $(a \rightarrow \$)$. Lacan (2003), ao se referir à produção capitalista, afirma ser a mais-valia "a causa do desejo do qual uma economia faz seu princípio: o da produção extensiva, portanto insaciável, da falta-de-gozar" (p. 434).

O princípio da produção extensiva da falta-de-gozar, representado pela fórmula $(a \rightarrow \$)$ que se constitui a partir do Discurso do Capitalismo, é o que promove a destituição do sujeito e da fantasia de acordo com parâmetros científicos. A incidência desse Discurso na universalização do sujeito se articula aos efeitos de segregação pela via do gozo. Sobre isso, é possível recuperar uma afirmação de Lacan (2003, p. 533) que, em resposta a uma interrogação sobre a escalada do racismo, propõe: "No desatino de nosso gozo, só há o Outro para situá-lo". Pode-se compreender que a única orientação para o gozo pelo qual se universaliza o sujeito provém de um Outro que, quanto ao racismo, deve ser rejeitado. O rechaço ao gozo do Outro é a ferramenta dos imperialismos que, favoráveis ao Mercado Comum, remanejam massas humanas.

\section{O campo de concentração como precursor e matriz}

Ao propor o encontro entre o objeto fabricado pela ciência e o sujeito, o Discurso do Capitalismo enfatiza a purificação do sujeito promovida por aquela. Assim, esse sujeito se reduz, é incorporado a determinada categoria, à condição do rechaço de sua singularidade. A proposta de que esse processo pode ser entendido a partir do modelo do campo de concentração encontra auxílio para sua fundamentação nas afirmações de Agamben (1995, p. 162) a respeito desse modelo:

Ao invés de deduzir a definição do campo a partir dos eventos que aí se desenrolam, nos perguntamos antes: o que é um campo, qual sua estrutura jurídico-política, por que semelhantes eventos aí puderam ter lugar? Isto nos levará a olhar o campo não como um fato histórico e uma anomalia pertencente ao passado (mesmo que, eventualmente, ainda verificável), mas, de algum modo, como a matriz oculta, o nómos do espaço político em que ainda vivemos.

A interrogação acerca do estatuto jurídico e político do campo de concentração expande a incidência do que é materializado sem estar circunscrito ao passado sombrio de uma guerra de proporções mundiais. Esse espaço político remete ao que o filósofo italiano reconhece como estado de exceção em sua mais plena soberania e 
prática. O campo torna-se assim um território (não necessariamente em termos físicos) exterior às coordenadas do ordenamento jurídico, embora sua presença de fato esteja assentada sobre um território interno a essas ordenações legais. Segundo o autor, esse espaço conjuga, em um conjunto indissociável, o que ele define como vida nua e a norma.

A respeito do termo vida nua é preciso esclarecer que Agamben (1995) recorre à definição aristotélica que define vida em dois seguimentos: bíos, que se refere ao modo de viver próprio de uma pessoa ou de um grupo; zoé, que exprime a vida nua, ou seja, o simples viver dos seres humanos, animais e deuses. A última é excluída do mundo clássico e da pólis grega em função da hierarquização que compreende que a vida política, pautada na linguagem, é superior e soberana. Essa exclusão não coincide com uma extinção da vida nua, que vem a se tornar estratégica na aposta política da modernidade. O docilizar da vida nua contou com o aparato tecnológico forjado pela soberania do biopoder. O Estado moderno centraliza em seus cálculos a vida biológica, e a esta impõe regras por possuí-la à sua disposição.

O poder soberano dispor da vida significa, todavia, que a morte está em jogo. Dentro desse domínio, Agamben (1995) recupera do direito romano arcaico a figura do homo sacer, o qual tem a vida nua totalmente disponível à soberania. Essa figura tem, na modernidade, um significado emancipado daquele que era atribuído na antiguidade ao sacrifício. Afirma o autor que "o que temos hoje diante dos olhos é, de fato, uma vida exposta como tal a uma violência sem precedentes, mais precisamente nas formas mais profanas e banais" (p. 121). Essa vida torna-se matável pela via da banalidade. Se o campo de concentração e de extermínio reúne de forma indissociável a vida nua e a norma, esse espaço prevalece em razão dessa vida ser matável.

A banalização da vida sob o poder da violência sem precedentes já havia sido indicada por Arendt (2012, p. 582) em sua reflexão sobre o regime totalitário e os campos de concentração, que "destinam-se não apenas a exterminar pessoas e degradar seres humanos, mas também servem à chocante experiência da eliminação, em condições cientificamente controladas, da própria espontaneidade como expressão da conduta humana, e da transformação da personalidade humana numa simples coisa".

Arendt (2012) corrobora a proposta de destituição subjetiva pela ciência ao conceber o campo de concentração, para além do extermínio e da degradação, como redução do humano em condições controladas. É possível compreender a proposição da autora sobre a transformação do humano em coisa como uma forma de destituição similar àquela que Lacan (2003a) atribuía à ciência. Ainda segundo a autora, 
a experiência dos campos de concentração demonstra realmente que os seres humanos podem transformar-se em espécimes do animal humano, e que a 'natureza' do homem só é 'humana' na medida em que dá ao homem a possibilidade de tornar-se algo eminentemente não natural, isto é, um homem (Arendt, 2012, p. 602-603).

Conforme problematizamos com Lacan (1967), há um preço a ser pago pelo ser falante que pode ser atribuído ao velamento da estrutura na qual o sujeito se divide em sua relação com o objeto a. A concentração das massas humanas universaliza o ser falante não como um animal ou mesmo como cadáver, mas pela destituição da própria relação com a linguagem. Assim, o campo é a materialização de um estado de exceção em que se configura o limiar de indistinção entre a norma e a vida nua. Esse estado, segundo Agamben (1995), presentifica-se toda vez que tal estrutura se organiza independentemente da natureza dos crimes praticados e de uma determinação topográfica. A saber, o campo de concentração "como localização deslocante é a matriz oculta da política em que ainda vivemos, que devemos aprender a reconhecer através de todas as suas metamorfoses, nas zones d'attente de nossos aeroportos bem como em certas periferias de nossas cidades" (Agamben, 1995, p. 171).

O estado de exceção como regra configura a matriz do que o filósofo define como campo em sua projeção além da localização geográfica. Tal matriz se alinha ao que já indicamos no ensino de Lacan, especialmente nos trabalhos de 1967, como efetivação dos efeitos de segregação. Esses efeitos teriam, assim, como precursores os campos de extermínio nazistas, reconhecidos por Lacan (2003a) em um horizonte que implica a psicanálise.

\section{Considerações finais}

Ao interrogar se o campo de concentração se articula ao que é da ordem de que se torna partilhável, frisamos a importância de levar em consideração o estatuto do objeto partilhável ou não para alcançar a discussão sobre o processo de segregação como aquilo que mantém separadas massas humanas fadadas ao mesmo espaço. A sociedade vetorizada pela ciência tem como consequência 0 remanejamento das massas orientado pela universalização promovida pela própria ciência. Tal universalização é traduzida em termos de um sujeito puro, fundamento da prática de concentração de massas humanas, e é agenciada pelo horizonte de Mercados Comuns. O sujeito derivado do saber científico se articula aos remanejamentos 
das hierarquias sociais e possui velada a estrutura fantasmática $(\$ \diamond$ a). Há um preço a ser pago pelo ser falante que pode ser atribuído ao velamento da estrutura na qual o sujeito se divide em sua relação com o objeto a. A concentração das massas humanas universaliza o ser falante pela destituição da relação com a linguagem.

A universalização de um sujeito puro supõe que a divisão seja extirpada em nome de um encontro forjado com o gozo. Esse encontro, que pode ser simbolizado como $(a \rightarrow \$)$, tem como fundamento a destituição subjetiva operada pela ciência e remete aos precursores campos de concentração, na medida em que reduz a divisão do sujeito assim incorporado a uma categoria disponibilizada no Mercado Comum. É importante destacar que a ideia do sujeito puro é associada por Lacan (1967) ao progresso científico e não tomada como exclusividade do Discurso do Capitalismo. Essa articulação entre o progresso da ciência e o Discurso do Capitalismo forja o encontro com o objeto de gozo e impele o processo de destituição subjetiva. O velamento da divisão e a destituição da estrutura fantasmática podem ser compreendidos como a disponibilização do que ocuparia o lugar de resto no Mercado Comum. O futuro de Mercado Comum se equilibra, desse modo, em um efeito de segregação que anula a divisão em nome da estratificação.

\section{Referências}

Agamben, G. (1995). Homo sacer: O poder soberano e a vida nua. Belo Horizonte: Editora UFMG.

Arendt, H. (2012). Origens do totalitarismo. São Paulo: Companhia das Letras. (Originalmente publicado em 1951).

Brousse. M-H. (2002). O inconsciente é a política. São Paulo: Escola Brasileira de Psicanálise.

Freud, S. (1996a). Projeto para uma psicologia científica. In Edição Standard Brasileira das obras psicológicas completas de Sigmund Freud (Vol. 1. pp. 335-468). Rio de Janeiro: Imago. (Trabalho de 1895 originalmente publicado em 1950).

Freud, S. (1996b). Análise de uma fobia em um menino de cinco anos. In Edição Standard Brasileira das obras psicológicas completas de Sigmund Freud (Vol. 10 pp. 13-133). Rio de Janeiro: I mago. (Trabalho originalmente publicado em 1909).

Freud, S. (1996c). Inibições, sintomas e ansiedade. In Edição Standard Brasileira das obras psicológicas completas de Sigmund Freud (Vol. 20. pp. 81-177) Rio de Janeiro: Imago. (Trabalho originalmente publicado em 1926[1925]).

Lacan, J. (1998). O estádio do espelho como formador da função do eu. In J. Lacan, Escritos (V. Ribeiro, Trad.; pp. 96-103). Rio de Janeiro: J orge Zahar. (Texto originalmente publicado em 1949). 
Lacan, J. (2008). O Seminário, livro 7: a ética da psicanálise. Rio de Janeiro: Jorge Zahar. (Seminário originalmente proferido em 1959-1960).

Lacan, J. (2005). O Seminário, livro 10: a angústia. Rio de Janeiro: Jorge Zahar. (Seminário originalmente proferido em 19621963).

Lacan, J. (1967-68). O Seminário, livro 15: o ato psicanalítico. (Seminário originalmente proferido em 1967-1968).

Lacan, J. (1992). O Seminário, livro 17: o avesso da psicanálise. Rio de Janeiro: Jorge Zahar. (Seminário originalmente proferido em 1969-1970).

Lacan, J. (2003). Radiofonia. In J. Lacan, Outros escritos (pp. 400447). Rio de Janeiro: Jorge Zahar. (Texto originalmente publicado em 1970).

Lacan, J. (2003a). Alocução sobre as psicoses da criança. In J. Lacan, Outros escritos (pp. 359-368). Rio de Janeiro: Jorge Zahar. (Texto originalmente publicado em 1967).

Lacan, J. (2003b). Proposição de 9 de outubro de 1967 sobre o psicanalista da escola. In J. Lacan, Outros escritos (pp. 248264). Rio de Janeiro: Jorge Zahar. (Texto originalmente publicado em 1967).

Lacan, J. (2003c). Televisão. In J. Lacan, Outros escritos (pp. 508543). Rio de Janeiro: Jorge Zahar. (Texto originalmente publicado em 1974).

Lacan, J. (1978). Discours de Jacques Lacan à l'Université de Milan, le 12 mai 1972. In J. Lacan, Lacan in Italia. Milão: La Salamandra.

Lacan, J. (1967). Breve discurso a los psiquiatras. Retirado de http://e-diciones-elp. net/images/secciones/novedades/L-6711-10.pdf

Rabinovich, D. S. (2009). O conceito de objeto na teoria psicanalítica. Rio de Janeiro: Companhia de Freud.

\section{Endereço para correspondência \\ Marcos Vinicius Brunhari}

Universidade do Estado do Rio de Janeiro - UERJ

Instituto de Psicologia

Rua São Francisco Xavier, 524, Maracanã, CEP 20550-900, Rio de Janeiro - RJ, Brasil

Endereço eletrônico: mvbrunhari@gmail.com

\section{Vinicius Anciães Darriba}

Universidade do Estado do Rio de Janeiro - UERJ

Instituto de Psicologia

Rua São Francisco Xavier, 524, Maracanã, CEP 20550-900, Rio de Janeiro - RJ, Brasil

Endereço eletrônico: viniciusdarriba@gmail.com.br 
Recebido em: 09/12/2018

Reformulado em: 10/01/2019

Aceito em: 18/01/2019

\section{Notas}

* Psicanalista. Doutor em Psicologia Clínica pela Universidade de São Paulo (IPUSP). Pós-doutorando pelo Programa de Pós-graduação em Psicanálise da Universidade do Estado do Rio de Janeiro (UERJ). Bolsista CAPES.

** Professor do Instituto de Psicologia da Universidade do Estado do Rio de Janeiro (UERJ), Programa de Pós-graduação em Psicanálise. Bolsista Produtividade CNPQ PQ2.

O presente trabalho foi realizado com apoio da Coordenação de Aperfeiçoamento de Pessoal de Nível Superior - Brasil (CAPES)

Este artigo de revista Estudos e Pesquisas em Psicologia é licenciado sob uma Licença Creative Commons Atribuição-Não Comercial 3.0 Não Adaptada. 